\title{
El montaje digital de imágenes o matte painting digital. Estado de la cuestión y conexión en el contexto internacional
}

Omar Adeeb Mohammad Alshboul ${ }^{\star}$ Universidad de Granada, España

RECIBIDO: 17.03.2014 / ACEPTADO: 29.03.2016

\begin{abstract}
Resumen
Frente a la escasez de recursos bibliográficos y referencias sobre esta técnica en idioma español, con el presente estudio tratamos de aproximarnos a la técnica de montaje digital de imágenes en la escenografía virtual. Se pretende ofrecer una referencia básica sobre cuál es el propósito del montaje digital de imágenes en el cine, sus orígenes y los autores más destacados que se valieron de esta técnica en sus películas.
\end{abstract}

Asimismo, procederemos a exponer el modo en que el montaje de imágenes ha sido introducido en el cine, y a abordar los problemas relacionados con su aplicación, centrándonos en la realidad y los retos del uso de esta técnica en España.

Desde la experiencia investigadora y científica sobre la técnica en cuestión, el autor ha conseguido identificar cuáles son los aspectos que mayormente impiden la consolidación de la técnica en los distintos ámbitos de su aplicación a nivel nacional (sobre todo en la industria cinematográfica), para ofrecer a continuación una serie de propuestas que, a su juicio, contribuirán a su afianzamiento como una técnica digital de innumerables posibilidades artísticas y creativas.

Palabras clave: Montaje digital, escenografía virtual, tecnología, fondo, fotografía.

\section{Matte painting. State of the art and in the international context connection}

\begin{abstract}
Before this research started, a major issue was faced: the lack of bibliography in Spanish language, either that written in Spanish or translated into Spanish from other language.

The above-mentioned issue had a demotivating effect on proceeding with the research work, nonetheless, in order to find solutions to the obstacles it faces and to find out the factors influencing the lack of such bibliography in Spanish, the research was finally carried out.
\end{abstract}

This study targets the Digital Matte Painting technique: how it works, a brief history of the technique, some authors and films that were elaborated using it.

The way in which this technique has helped in films will also be mentioned. Certain problems related to it will be presented, focusing on its status in Spain.

Throughout his research and scientific experience in the specific technique, the author has been able to identify the obstacles that mostly prevent its consolidation in all areas of its application at the national level (mainly in the film 
industry). The author therefore provides a set of suggestions that, in his opinion, would contribute in its reinforcement as a digital technique for countless artistic and creative possibilities.

Keywords: Digital Matte Painting, virtual scenography, technology, background, photography.

Progress is impossible without change

George Bernard Shaw

\section{Introducción}

Numerosos autores han formulado definiciones de la técnica del montaje de imágenes y de las razones por las que se consideró importante encontrar una manera para crear en el cine un escenario inexistente en la vida real, con el fin de proporcionar al espectador una 'imagen completa' del escenario de la película. La utilidad de la técnica se describe con claridad por Okun y Zwerman (2013):

Filmmaking is telling stories and stories take place is settings that must be depicted visually. Sometimes these settings exist in reality. And the filmmaker can travel to that location to shoot, but in many cases, the setting must be fabricated in some way. Very early on, Matte Painting became an important tool to create setting is a cost-effective and efficient manner. Matte Paintings help tell stories that would be impossible without them for technical, logistical and budgetary reasons. ${ }^{1}$

Ambos autores hacen hincapié también en las grandes posibilidades artísticas y creativas que permite la técnica de montaje de imágenes o fondos pintados, independientemente de la tecnología, en la transmisión de diferentes dimensiones espacio-temporales al espectador:

Matte Painting has been and always will be a vital ingredient in expanding the scope of filmmaker's visions, regardless of technology. It is a necessary element in the filmmaker's toolbox. Matte Paintings transport the audience to past eras or take them deep into the future to discover new and exciting worlds. They make it possible to filmmakers to keep production costs down and to give scale and importance to settings. Matte Paintings are needed so viewers can see clearly. They are needed to tell viewers where they are. ${ }^{2}$

\section{Antecedentes de la técnica}

El montaje de imágenes es una herramienta de la escenografía tradicional que surgió a principios del siglo XX para crear fondos de escenarios imaginarios (los llamados 'platós cinematográficos').

A lo largo de su historia, varios investigadores y profesionales del cine, especialmente los escenógrafos, trabajaron para desarrollarla con el objetivo de llegar al mejor uso posible de la técnica. Los escenográfos tuvieron que desarrollar su capacidad creativa para crear escenarios con un porcentaje elevado de realismo para el espectador, empleando desde las técnicas más simples, en sus comienzos, hasta las sofisticadas técnicas digitales de la actualidad.

Hoy en día las técnicas visuales digitales tienen un uso fundamental en el mundo del cine y en otros campos relacionados. Estas técnicas han experimentado un desarrollo significativo desde que 
surgieron. En este proceso no podemos olvidar el papel de los escenógrafos en su perfección para llegar a los niveles de realismo que apreciamos en las producciones cinematográficas de los últimos años, gracias sobre todo a la incorporación de las técnicas visuales digitales y el desarrollo de sus aplicaciones en el cine.

\section{Definición}

El 'montaje de imágenes' no es un concepto que tenga una definición universal, sino que ha sido definido por numerosos autores y profesionales que, desde su experiencia con la técnica, han escrito sus opiniones y reflexiones sobre la misma.

Podemos afirmar que el montaje de imágenes, como "una técnica que nos permite crear cualquier tipo de escenario imaginario a partir de fotografías e ilustraciones que, a través de una combinación óptima, permiten obtener resultados realistas". Se trata entonces de crear digitalmente escenarios realistas para su integración en grabaciones reales. Con ello entendemos las múltiples aplicaciones profesionales de esta técnica en el ámbito cinematográfico, el editorial, en la publicidad o en la industria de los videojuegos.

Por ende, se puede afirmar que la base sobre la cual se sustenta la técnica del montaje de imágenes surgió con la idea de utilizar una o más pinturas de múltiples capas para sustituir un fondo. Sin embargo, y a pesar de tener inicialmente una concepción sencilla, se trata de una técnica muy hábil y desafiante desde la perspectiva artística, debido a que las pinturas utilizadas debían resultar suficientemente realistas y compatibles con el estilo de la película a fin de que los espectadores las perciban como un fondo real.

La técnica del montaje digital de imágenes en la actualidad se lleva a cabo diseñando pinturas a través del ordenador, y con la utilización de los programas de procesamiento y tratamiento de imagen.

¿Cómo se diseñaban tradicionalmente los fondos pintados?
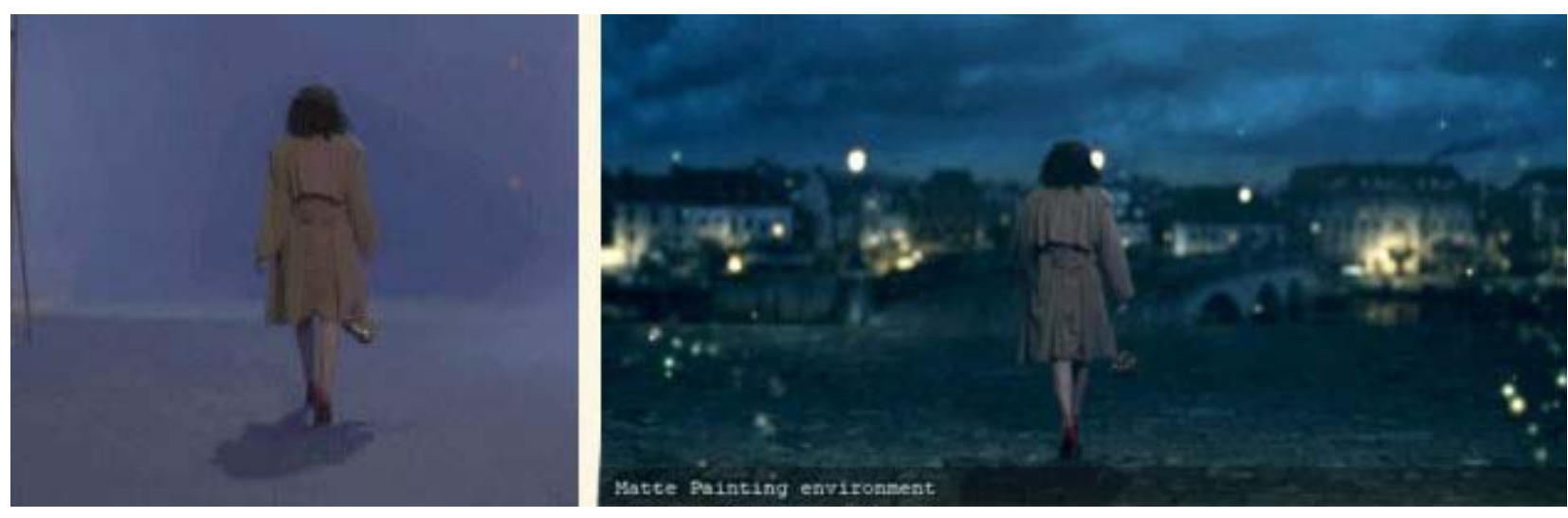

Fig. 1 (izda). Técnica tradicional de montaje de imágenes. Fig 2 (dcha). Montaje digital de imágenes en la actualidad.

La técnica consistía en aplicar capas de pintura (generalmente óleo) sobre un cristal, o panel de plexiglás, para después iluminar el resultado desde atrás. 
A las zonas que se deseaban más iluminadas se les aplicaban tonos más claros o menos pintura, mientras que las más oscuras se saturaban de pigmento para impedir que pase la luz. Si el escenario presentaba focos o puntos de luz, como estrellas, se dejaban pequeños puntos sin pintura para que permitan pasar toda la luz.

Después, bastaba con rodar la escena respetando la misma perspectiva de la pintura, y montar después el resultado en el estudio. Si el artista es especialmente habilidoso, el montaje de imágenes se funde perfectamente con la acción.

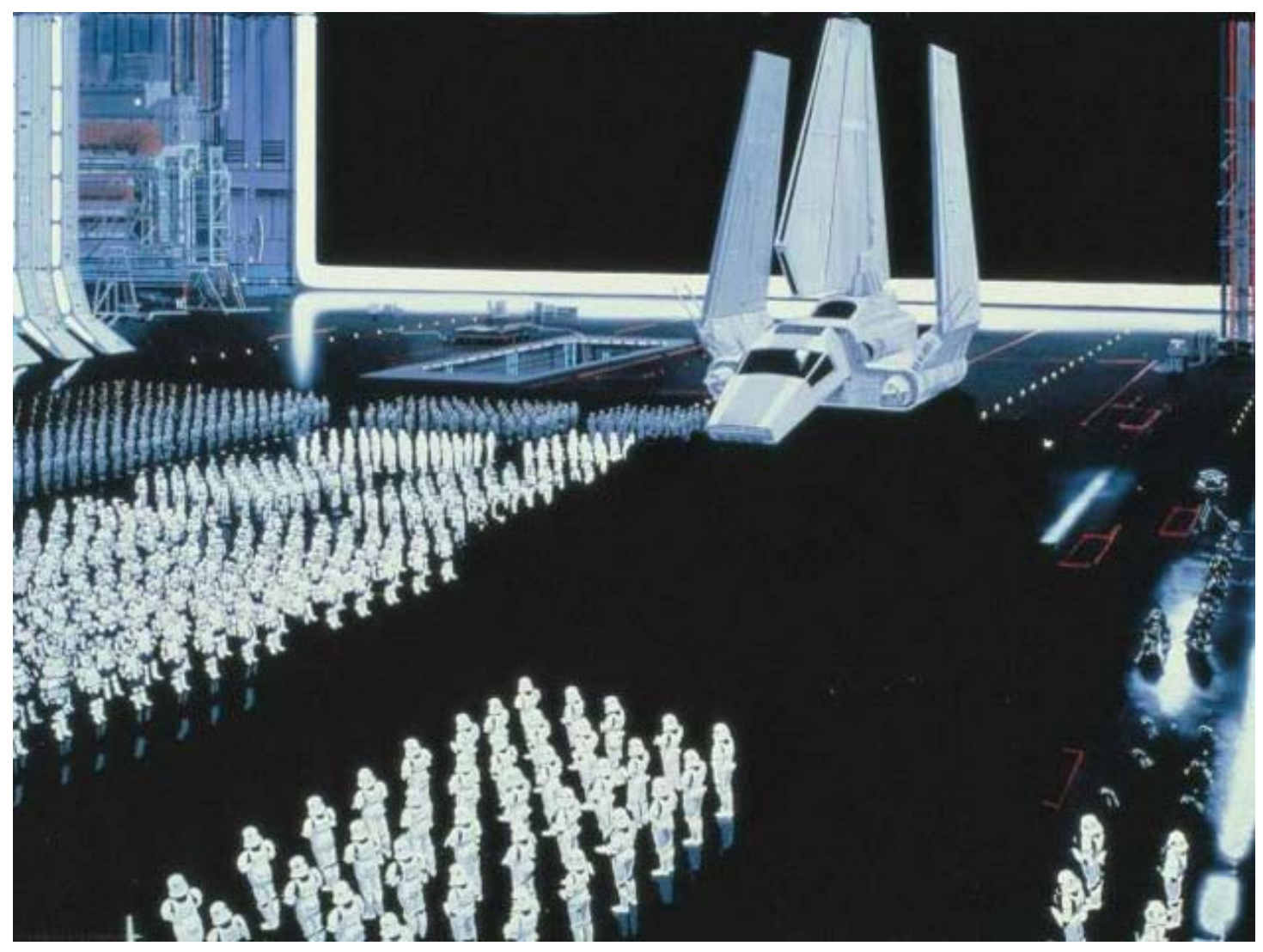

Fig. 3. Montaje de imágenes finalizado (Star Wars, 1977).

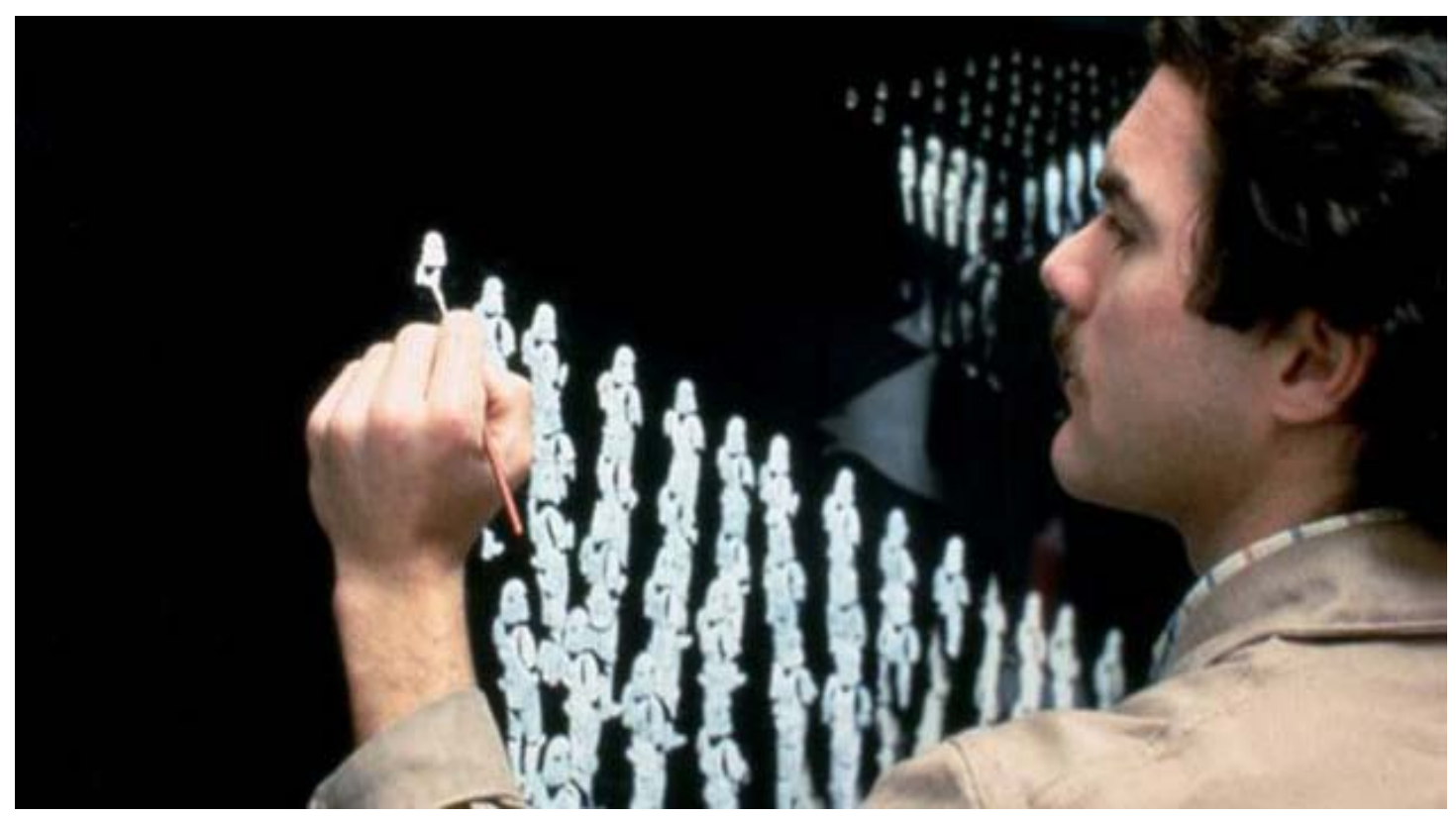

Fig. 4. Chris Evans trabajando uno de los escenarios virtuales (Star Wars, 1977). 


\section{Antecedentes}

Desde sus orígenes, fueron numerosos los intentos de trabajar con el montaje de imágenes para películas, aunque podemos considerar a Norman Dawn (1884-1975) como el precursor de esta técnica en el cine. En 1905, a través del tratamiento de la imagen de la fachada de una casa, Dawn consigue tapar los postes de telégrafos que aparecían pintando árboles en un cristal y colocándolo delante de la misma. Muy habilidoso manejando el pincel, alcanza con esta técnica unos niveles de precisión importantes y efectos visuales de gran realismo para el espectador de la época (la película Missions of California, 1907).

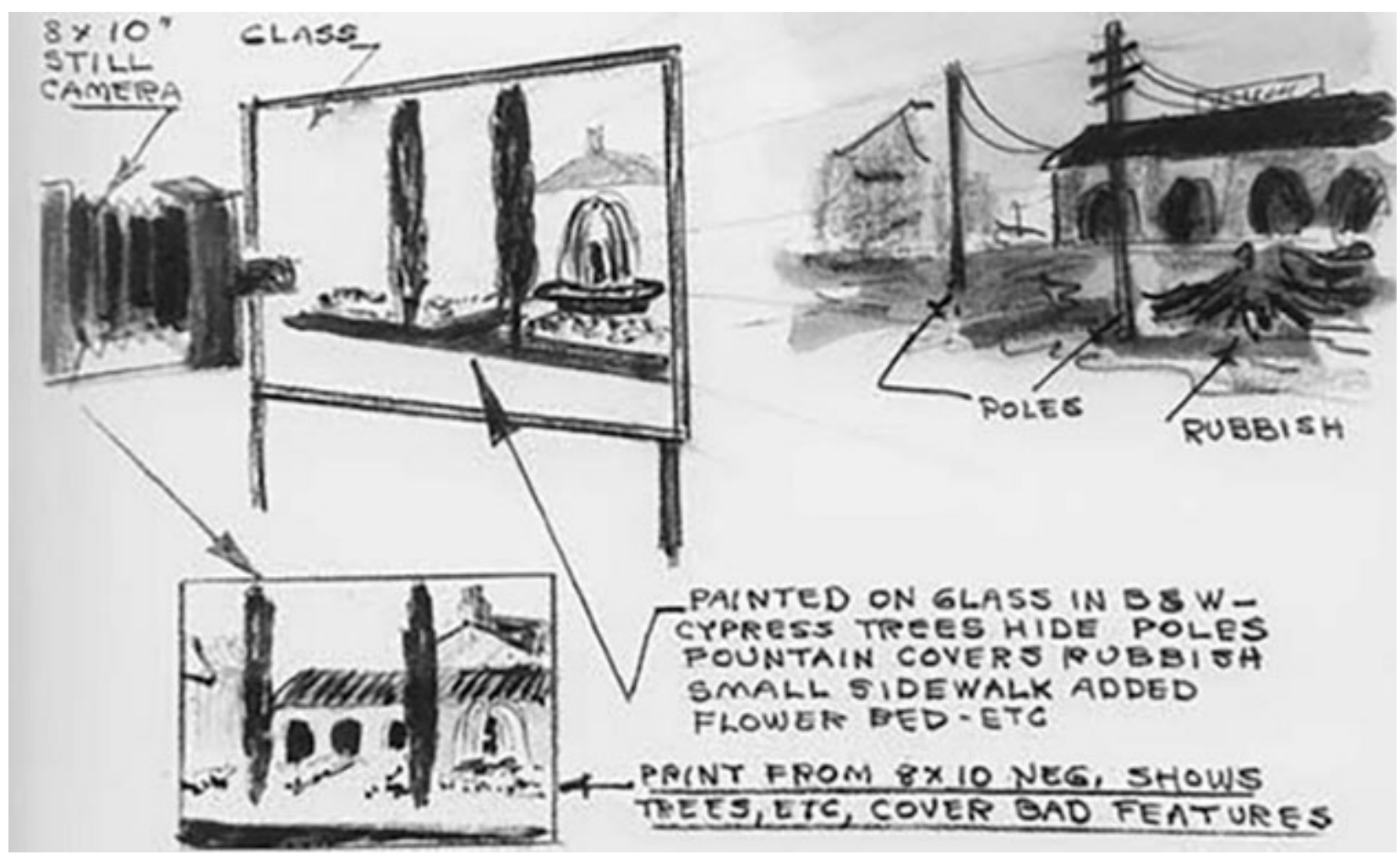

Fig. 5. Dibujo explicativo de la técnica del cristal usada por Dawn en 1905.

Años más tarde Dawn dirige sus primeras películas con una aplicación casi perfecta de los fondos pintados, reconstruyendo edificios y partes del entorno en las escenas, a través de su técnica.

La técnica se fue desarrollando hasta la creación de departamentos específicos en estudios como MGM y RKO, reconocidos a nivel mundial por su trabajo en el desarrollo de las aplicaciones del montaje digital de imágenes en el cine. La técnica decayó a finales de la década de los sesenta y a principios de los setenta, y con ello desaparecieron muchos de los departamentos relacionados con la misma.

Se revitalizó el interés por la técnica con lanzamiento de la primera película de "La Guerra de las Galaxias" (Star Wars) en 1977. Dirigida, producida y guiada por George Lucas, representa el primer proyecto exitoso de los fondos pintados con la utilización de efectos visuales con tratamiento digital.

A partir de este momento, y casi exclusivamente en la industria cinematográfica norteamericana, se sucedieron las películas que empleaban el montaje digital de imágenes.

La última escena rodada con la técnica de tradicional de fondos pintados que recordamos de una 
gran producción, fue la realizada por la compañía Matte World Digital para la película Titanic (1997), donde en una de las escenas finales de la película se combina un barco de rescate real con un dibujo digital del amanecer en un segundo plano.

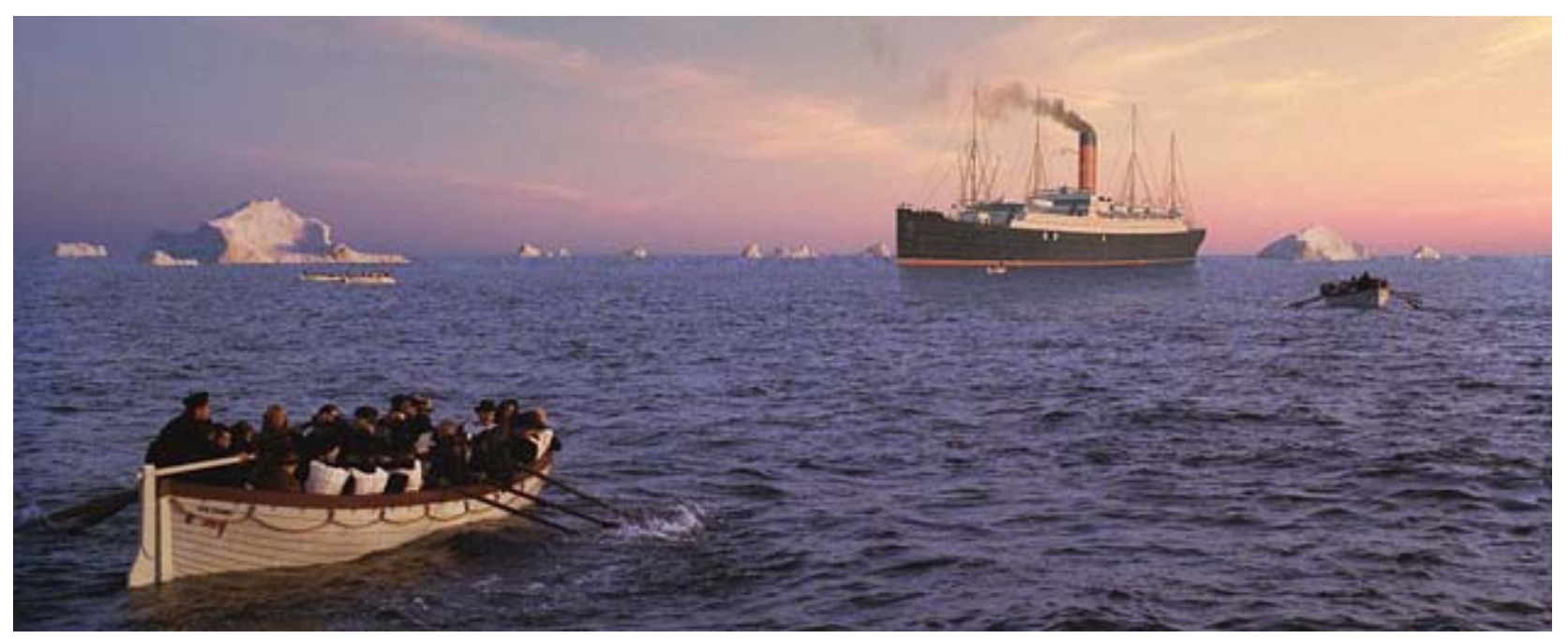

Fig. 6. Fotograma de la película Titanic (Dir. James Cameron), 1997.

Esta posibilidad de crear escenarios imaginarios y ofrecerlos al espectador de un modo altamente realista y coherente no sólo contribuyó al nacimiento de una nueva generación de escenógrafos, sino que además supuso el salto definitivo del cine hacia un nuevo género donde la imaginación del guionista se libera y rompe con los estándares establecidos hasta el momento, la "ciencia ficción".

Además, se produjo un desarrollo paralelo en las técnicas de tratamiento audiovisual en la industria cinematográfica (montaje), lo cual reforzó y consolidó el realismo en las representaciones del montaje digital de imágenes, sobre todo a partir de la década de los noventa.

A modo de síntesis, podemos apreciar cómo ha sido la evolución de la técnica, desde los escenarios diseñados manualmente a base de pinturas y contrastes de luz, colores, etc. en los años 30 y 40 del siglo XX (El Mago de Oz, Lo que el viento se llevó o Ciudadano Kane) hasta la creación de escenarios imaginarios de grandes dimensiones y con grandes dotes de realismo para el espectador del cine: Titanic (1997), The Matrix (1999), El Señor de los Anillos (2001, 2002, 2003), Avatar (2009) o Exodus (2014).

A la hora de hablar de Matte Painting digital resulta necesario destacar el gran trabajo de Dylan Cole, quien a través de esta técnica ofreció obras memorables en las taquillas del cine: El Señor de los Anillos, Fast and Furious o The Aviator.

Mencionamos la película Daredevil como ejemplo representativo del trabajo de Dylan Cole a través del montaje digital de imágenes, mostrando fondos a través de múltiples capas, y no mediante escenarios reales: 


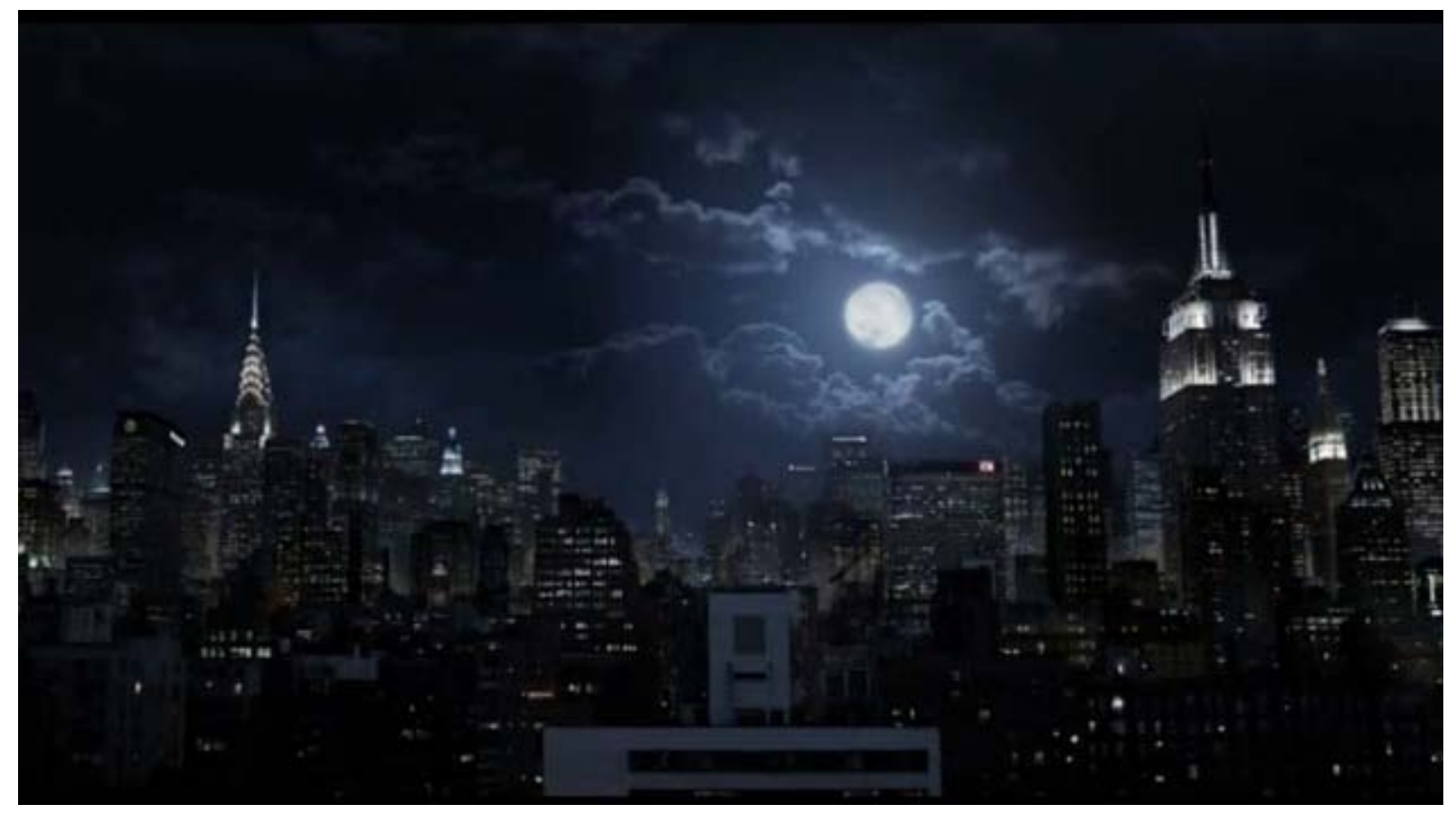

Fig. 7. Fondo de escenario (resultado final de montaje digital de imágenes).

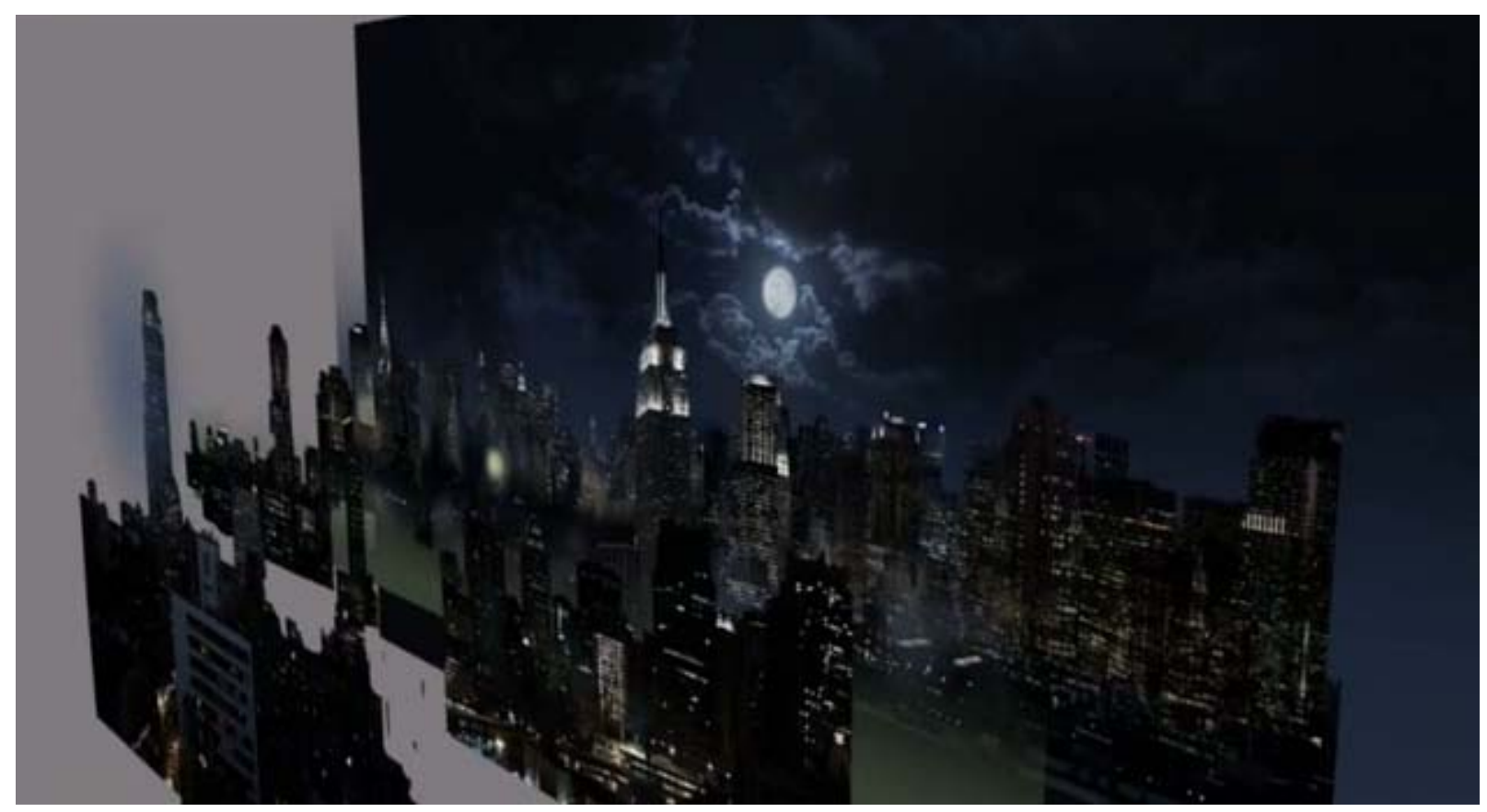

Fig. 8. Fondo de escenario (montaje digital de imágenes a través de múltiples capas).

\section{El Señor de los Anillos: La consagración del montaje digital de imágenes en el cine}

La trilogía El Señor de los Anillos es considerada como la obra que ha consagrado definitivamente la fusión de los conceptos técnicos de montaje digital de imágenes, la escenografía tradicional y la perspectiva. Esta trilogía nos brindó infinidad de efectos visuales y digitales, además de ser una de las máximas representaciones cinematográficas de la técnica del trampantojo o arte de 'engañar' con la perspectiva.

Otra técnica constante en la obra y determinante para la composición final fue la pintura digital, que en combinación con las herramientas de edición digital de subexposición y sobreexposición, ha permitido manejar y ajustar los niveles de luz de la escenas o incrementar el contraste de forma local, lo cual ha hecho posible el control de la exposición de forma manual por parte de los editores. 


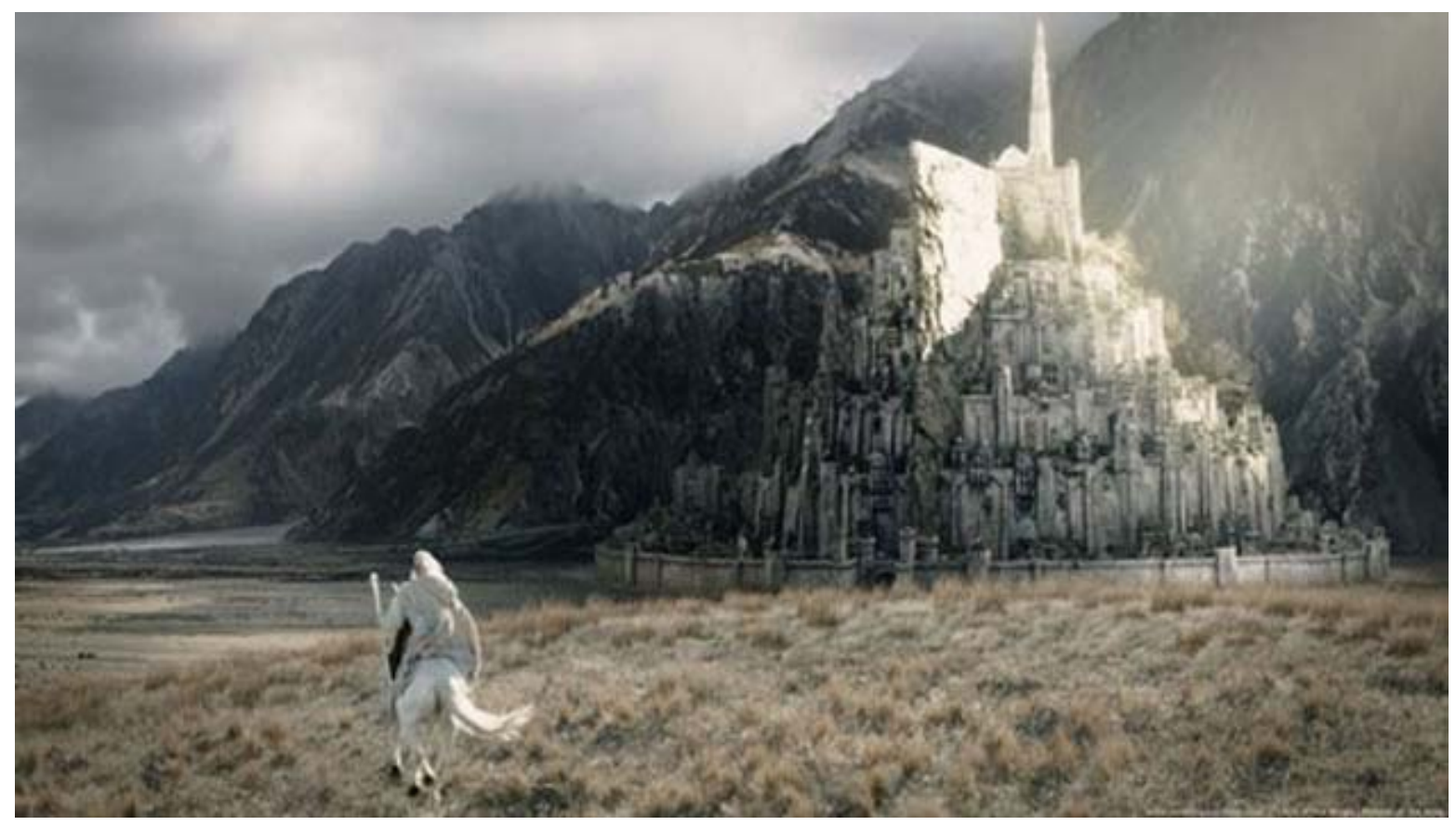

Fig. 9. Fotograma de El Señor de los Anillos (2001-2003).

Otro de los aspectos a destacar es el empleo de 'dobles a escala', grandes y pequeños en muchas de las escenas, e incluso los editores llegaron a diseñar duplicados de los escenarios, en dos escalas diferentes, con el fin de que los diferentes personajes de la obra se apropiaran de manera proporcionada a su respectivo tamaño.
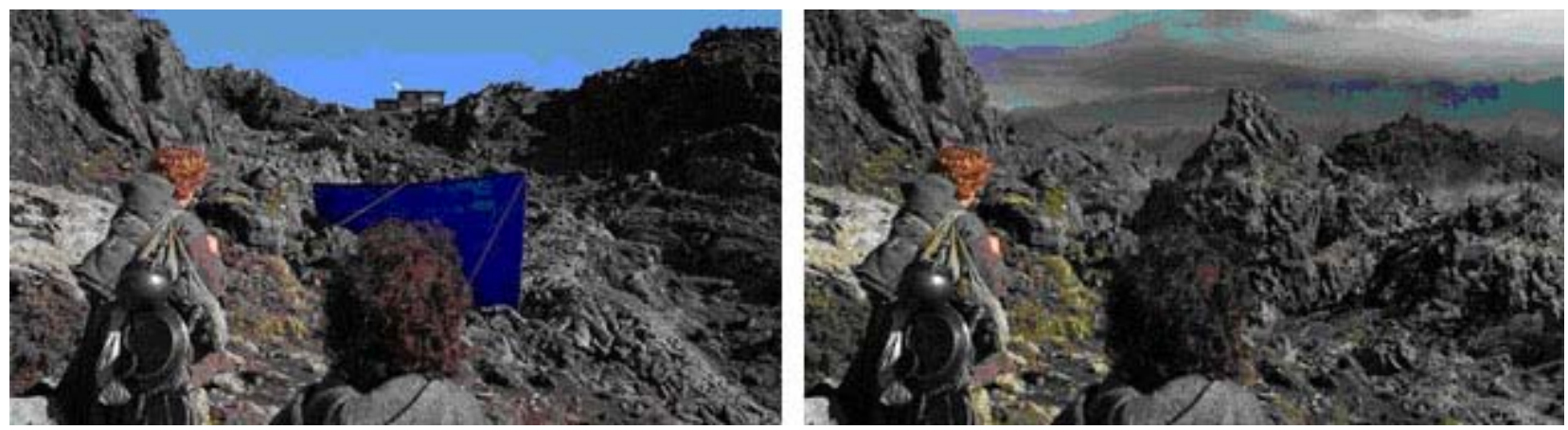

Fig. 10. Ejemplo de duplicado a escala del mismo escenario (El Señor de los Anillos, 2001-2003).

Montaje digital de imágenes en el cine español: Realidad y Antecedentes de la técnica en

\section{España}

Si bien consideramos a Dawn el 'padre' del montaje con fondos pintados en el cine a nivel mundial, en el ámbito nacional fue de la mano de Emilio Ruiz del Río (1923-2007) que esta técnica comienza a cobrar protagonismo en el cine español. Pintor mate de reconocimiento internacional en el mundo de las artes visuales, Ruiz del Río cuenta con un amplio currículo de aportaciones a través del montaje de imágenes en el cine, con más de 450 colaboraciones en películas de éxito como Lawrence de Arabia o Doctor Zhivago, entre otras. Otra de las figuras clave, del cine español en este sentido, fue el director de arte Gil Parrondo, que saltó a la fama con películas que marcaron una época, como Patton (1970) y Nicolás y Alejandra, ambas ganadoras de premios Oscar. 
Para enfocar el trabajo de Ruiz del Río, tomaremos como ejemplo su última película (El Laberinto del Fauno, 2006) dirigida por Guillermo del Toro, y en la que utiliza varias técnicas visuales y efectos especiales de montaje de imágenes de gran precisión para crear escenarios imaginarios. Esta película formó parte de una trilogía de películas sobre la guerra civil española, con numerosas escenas fantásticas. Además, Ruiz del Río recurre en algunas de las escenas a la técnica del croma o 'llave de color' debido en gran medida al limitado presupuesto de la obra. Ésto supuso para el espectador dificultades en la percepción visual de determinadas escenas de la película, que le resultaban poco excitantes o de difícil interpretación.

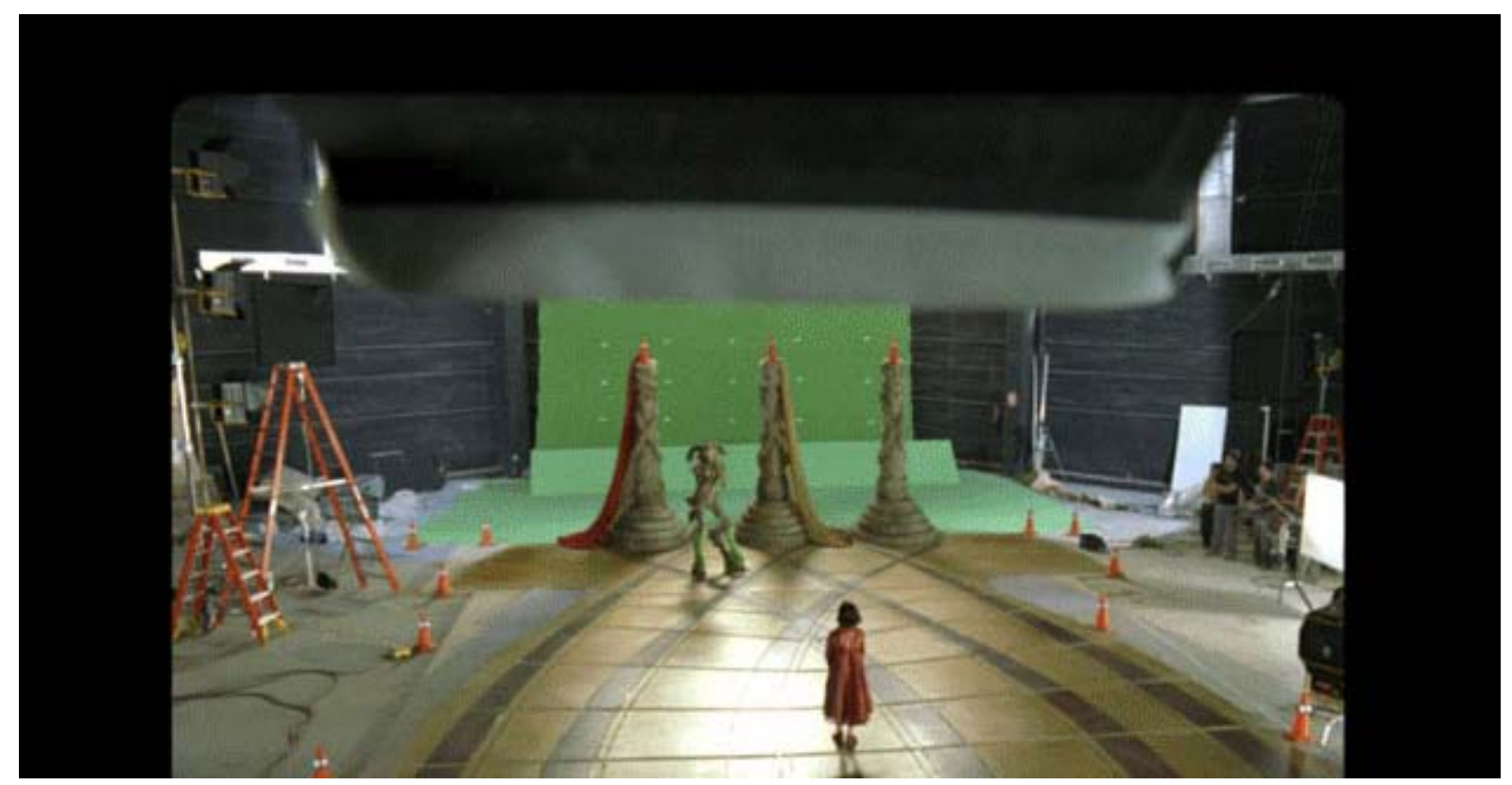

Fig. 11. Montaje de un escenario creado por Ruiz del Río (El Laberinto del Fauno, 2006).

\section{A modo de conclusión}

A través de nuestras investigaciones, experiencias y contacto con el mundo del montaje digital de imágenes en España, podemos afirmar que esta técnica todavía no ha experimentado un auge significativo, sobre todo en la industria cinematográfica, lo que a nuestro juicio se puede atribuir a diferentes factores:

Recursos humanos: El escaso número de profesionales españoles con la formación y la cualificación necesarias para llevar a cabo grandes proyectos de montaje digital ha optado, en su mayoría, por emigrar a países en los que la demanda de proyectos de este tipo es elevada en la industria cinematográfica, especialmente y casi de manera exclusiva a los EE.UU., donde el género de la ciencia-ficción ofrece un mercado de trabajo de alta rentabilidad para estos profesionales. Por lo tanto, y tomando esto en consideración, resulta evidente el hecho de que el proceso de transmisión de conocimientos y de capacitación profesional sea limitado en lo que se refiere a las técnicas de montaje digital de imágenes en España.

Por otra parte, cabe señalar que la industria del cine en los EE.UU. ha encontrado en países como España una manera para reducir los costes del personal especializado en las técnicas de montaje digital, a través de la contratación temporal y para proyectos específicos de jóvenes talentos que 
buscan una oportunidad para dar a conocer su trabajo y dar el salto hacia Hollywood. Esto resume la idea de que la visión de estos jóvenes se limita a la realización un trabajo encomendado, guiados por intenciones individualizadas y careciendo de cualquier iniciativa de innovación.

Investigación: Las investigaciones en el campo de las técnicas digitales de diseño en general, y en particular las relacionadas con el montaje creativo de imágenes, son significativamente escasas en España. Podemos atribuirlo a que la gran mayoría de los recursos disponibles (bibliográficos, material gráfico, etc.), y los programas y aplicaciones informáticas de montaje digital están disponibles en otros idiomas, sobre todo el inglés. Además, este campo no cuenta con el respaldo necesario de las iniciativas estatales de fomento de la investigación (subvenciones, creación de centros de formación especializados, etc.) siendo uno de los campos menos explorados, debido especialmente a su reciente aparición en la industria cinematográfica del país.

Monopolio tecnológico: Existen grandes multinacionales tecnológicas que ejercen un claro monopolio a nivel mundial sobre las técnicas avanzadas del montaje digital de imágenes (softwares, nuevas técnicas creativas, etc.), contando constantemente con las mejores innovaciones tecnológicas y aumentando cada vez más la 'brecha tecnológica' con las empresas que han hecho un intento para introducirse en este sector. Estas multinacionales disponen de los recursos necesarios para llevar a cabo los proyectos de montaje digital más importantes en Hollywood, tanto económicos como humanos y tecnológicos.

Con lo expuesto queremos poner de manifiesto que el montaje digital a nivel nacional no es una técnica desconocida o inexistente en las producciones cinematográficas, sino que se trata de una técnica en cierto modo 'descuidada' teniendo en cuenta las grandes posibilidades creativas y estéticas que ofrece al director de arte de una película, siempre al servicio del éxito visual y escenográfico de la obra.

El desarrollo de las aplicaciones de montaje digital de imágenes en general, y en el cine español en especial, sigue siendo una asignatura pendiente para los profesionales del sector (directores de arte, técnicos dibujantes, etc.) que no terminan de encontrar la fórmula para 'despegar' con la técnica y consolidarla como un elemento visual creativo determinante en la industria cinematográfica del país.

Aquí debemos mencionar una película que consideramos como un claro ejemplo y un modelo de referencia para los directores nacionales, dirigida por el español Juan Antonio Bayona (The Imposible, 2012). Esta obra de éxito internacional contó con la colaboración de profesionales españoles de gran prestigio como Óscar Faura (director de fotografía) o Pilar Revuelta (directora de arte y Óscar a la Mejor Dirección Artística con El laberinto del fauno en 2008, una producción conjunta entre productoras españolas y mexicanas).

A la luz de lo expuesto sobre los problemas y los retos del desarrollo de las técnicas del montaje digital en España, se proponen una serie de soluciones que, desde su perspectiva personal y su experiencia en el mundo del diseño digital, podrían contribuir a la expansión de estas técnicas no sólo en el sector cinematográfico sino también en el resto de los sectores relacionados (editoriales, publicidad, etc.): 
Primero. El impulso de la investigación sobre las técnicas del montaje digital, lo que sin duda pasará por la traducción al español de las obras más relevantes sobre el tema (en su mayoría en inglés) y la publicación de obras de investigadores y expertos nacionales.

Segundo. La puesta en marcha de políticas, a nivel estatal, orientadas a fomentar el retorno de los talentos y expertos españoles en las técnicas del montaje digital, con el fin de aprovechar su experiencia y su cualificación para la formación de nuevos expertos y ampliar la base de recursos humanos en el país.

Tercero. Generalizar en los planes de estudio la impartición de materias relacionadas con el diseño en general, y especialmente el montaje digital de imágenes en las escuelas de diseño y las facultades de bellas artes.

Cuarto. El Estado debe promocionar y subvencionar las iniciativas de las empresas del sector privado que emprendan acciones encaminadas a importar las nuevas tecnologías y las técnicas más creativas y modernas del montaje digital.

Quinto. El impulso y la promoción de jóvenes talentos a través de ciclos formativos específicos de técnicas de montaje digital en el extranjero.

Con todo ello pretendemos incrementar la conciencia sobre la importancia de las técnicas digitales del montaje de imágenes en el mundo del diseño digital creativo, un campo que a nivel mundial está cobrando cada vez más peso en investigaciones de carácter innovador y en sus aplicaciones prácticas en la industria cinematográfica principalmente, pero que a nivel nacional todavía no cuenta con una presencia notable en los términos señalados.

\footnotetext{
* Licenciado en Bellas Artes (especialidad Diseño de Interiores, Universidad de Yarmouk, Jordania). Máster en Dibujo y Diseño por la Universidad de Granada, donde actualmente es doctorando en Diseño de Interiores. Investigador con especial interés en el diseño en general, particularmente en el diseño de interiores, gráfico, digital y multimedia. Interés por completar la carrera investigadora con publicaciones y colaboraciones en revistas científicas de renombre del mundo del diseño. Correo-e: omaralshboul89@yahoo.com

1 "El arte cinematográfico se trata de narrar historias y las historias cobran vida en escenarios que deben ser descritos visualmente. A veces estos escenarios existen en realidad y el cineasta puede viajar hasta ese lugar; pero en muchas ocasiones, el escenario debe ser fabricado de algún modo. Desde muy temprano, la pintura mate se convirtió en una importante herramienta para crear escenarios de manera poco costosa y eficiente. La pintura mate ayuda a narrar historias que serían de otro modo imposible por razones técnicas, logísticas o presupuestarias."

2 "Afirman asimismo que: "La pintura mate siempre ha sido y siempre será un ingrediente vital para expandir el alcance de la visión del cineasta, independientemente de la tecnología. Es un elemento necesario de la caja de herramientas de un cineasta. La pintura mate transporta a la audiencia a eras pasadas o la lleva profundamente al futuro para descubrir mundos nuevos y emocionantes. La pintura mate le permite al cineasta mantener sus costos de producción bajos y al mismo tiempo darle escala e importancia a los escenarios. La pintura mate es necesaria para que los espectadores puedan ver claramente. Son necesarias para decirle a los espectadores en donde están."
}

\section{BIBLIOGRAFÍA}

COLE, D./ALTINER, A. D'artiste Matte Painting: Digital Artists Master Class. Ballistic Publishing, Australia 2005, pp. $13,20,33-52$.

JOHNSON, S. The Lord of the Rings and Vertical Limits Film Concessions and the Conservation Act 1987, 11, Butterworths Resource Management Bulletin 2002.

MATHIJS, E. The Lord of the Rings: Popular Culture in Global Context, Film studies, Wallflower Press 2006. 
MATTINGLY, D.B. The Digital Matte Painting Handbook. Wiley Publishing, Inc. Indiana, EE.UU. 2011. Chapter 4.

OKUN, J.A./ZWERMAN, S. Visual Effects Society Handbook: Workflow and Technique. Focal Press, Reino Unido 2013, pp. 574-580.

SAWICKI, M. Filming the Fantastic: A Guide to Visual Effects Cinematography. Elsevier, Inc. EE.UU. 2011. Chapter 3.

SERKIS, A. Gollum: How We Made Movie Magic, Harper Collins, London 2003.

SIBLEY, B. The Lord of the Rings: The Fellowship of the Ring Insider's Guide, Houghton Mifflin, 2001.

SIBLEY, B. Peter Jackson: A Film-maker's Journey, Harper Collins, London 2006

\section{REFERENCIAS ELECTRÓNICAS}

COLE, D. Demo Reel Video (Dylan Cole Studio) http://www.dylancolestudio.com/ (08.01.2016).

CORTÉS, J. Escenarios Digitales de "El Señor de Los Anillos", 2014. Documento electrónico,

<http://www.notodoanimacion.es/2014/05/escenarios-digitales-de-el-senor-de-los.html >(12.02.2016).

CLARK, F. Norman O. Dawn, 2015. Documento electrónico,

<http://fs-clark109508cp.blogspot.com.es/2015/10/norman-o-dawn.html >(01.03.2016).

DÍAZ, J. The Matte Paintings Of The Original Star Wars Trilogy And Their Creators, 2015. Documento electrónico, <http://www.gizmodo.com.au/2015/01/the-amazing-matte-paintings-from-star-warsand-their-creators/> (10.02.2016).

DI LULLO, T. 'Pan's Labyrinth': Partnering to Make Fantasy VFX a Reality, 2006. Documento electrónico, <http://www.awn.com/vfxworld/pans-labyrinth-partnering-make-fantasy-vfx-reality> (04.03.2016).

FAILES, I. Titanic Stories, 2012. Documento electrónico,

<https://www.fxguide.com/featured/titanic-stories/>(02.03.2016).

JOHNSON, D. Design and Illustration. Basic Principles of Digital Matte Painting, 2014. Documento electrónico, <http://design.tutsplus.com/articles/basic-principles-of-digital-matte-painting--psd-8970> (03.02.2016).

MAHER, M. Visual Effects: How Matte Paintings are Composited into Film, 2015. Documento electrónico <https://www.rocketstock.com/blog/visual-effects-matte-paintings-composited-film/ >(09.02.2016).

Visual Effects for Film. What is Matte Painting? , 2013 Documento electrónico,

<https://vfxforfilm.wordpress.com/2013/01/03/mattepainting/> (06.01.2016).

SEYMOUR, M. A vfx Labyrinth, 2007. Documento electrónico,

<https://www.fxguide.com/featured/a_vfx_labyrinth/ >(04.03.2016).

\section{IMÁGENES}

Fig. 1. Fuente: https://vfxforfilm.wordpress.com/2013/01/03/mattepainting/

Fig. 2. Fuente: https://vfxforfilm.wordpress.com/2013/01/03/mattepainting/

Fig. 3. Fuente: www.gizmodo.com.au/2015/01/the-amazing-matte-paintings-from-star-warsand-their-creators/

Fig. 4. Fuente: www.gizmodo.com.au/2015/01/the-amazing-matte-paintings-from-star-warsand-their-creators/

Fig. 5. Fuente: http://fs-clark109508cp.blogspot.com.es/2015/10/norman-o-dawn.html

Fig. 6. Fuente: https://www.fxguide.com/featured/titanic-stories/

Fig. 7. Fuente: https://www.youtube.com/watch?v=f3hL6ZAOeNc

Fig. 8. Fuente: https://www.youtube.com/watch?v=f3hL6ZAOeNc

Fig. 9. Fuente: http://www.notodoanimacion.es/2014/05/escenarios-digitales-de-el-senor-de-los.html

Fig. 10. Fuente: https://www.rocketstock.com/blog/visual-effects-matte-paintings-composited-film/

Fig. 11. Fuente: http://www.awn.com/vfxworld/pans-labyrinth-partnering-make-fantasy-vfx-reality

Fig. 12. Fuente: https://www.fxguide.com/featured/a_vfx_labyrinth/

Revista internacional de investigación, innovación y desarrollo en Diseño • ISSN 1889-433 x 